\title{
Immunoproteomic profile of Trichinella spiralis adult worm proteins recognized by early infection sera
}

Jing Yang, Wei Pan, Ximeng Sun, Xi Zhao, Gu Yuan, Qing Sun, Jingjing Huang and Xinping Zhu*

\begin{abstract}
Background: Trichinellosis, a widespread zoonosis, is regarded as an emerging or reemerging disease. Effective treatment and prognosis of trichinellosis depends on early diagnosis of the infection. The objective of this study was to identify sensitive and specific antigens for early diagnosis or effective vaccine antigens for preventing infection.
\end{abstract}

Methods: The somatic proteins of T. spiralis adult worms were separated by two-dimensional gel electrophoresis (2-DE). The separated proteins were probed with early infection sera from swine or mice infected with $T$. spiralis for 7 days. The primary immunoreactive spots were characterized by MALDI-TOF/TOF-MS analysis in combination with bioinformatics. The identified proteins were annotated using WEGO based on their functions. The immunodominant protein was chosen for expression as recombinant protein in E. coli and the purified recombinant protein was used to confirm its antigenicity by Western blot with the same infection sera.

Results: Approximately 300 spots were separated by 2-DE, with molecular weights ranging from 10 to $130 \mathrm{kDa}$, and $\mathrm{pl}$ values ranging from $\mathrm{pH} 4$ to 10. The sera from swine and mice infected with T. spiralis for 7 days recognized 64 proteins. MALDI-TOF/TOF-MS analysis identified 55 proteins, some with different isoforms. Finally, 40 individual immunoreactive proteins were obtained with a wide range of biological functions. Several proteins, such as heat shock protein 70, 14-3-3 protein, and cysteine protease could be used as immunodiagnostic or vaccine antigens. Among these identified proteins, the highly immunodominant Ts14-3-3 was chosen for expression in E. coli and purified recombinant Ts 14-3-3 was able to be strongly recognized by the same T. spiralis infected sera used for identifying these antigens, therefore the most promising antigen for early immunodiagnosis of Trichinella infection.

Conclusions: A total of 64 proteins from the adult worm were recognized by early infection sera from swine and mice infected with $T$. spiralis for 7 days. Several proteins, are of particular interest as immunodiagnostic or vaccine antigens, especially with Ts14-3-3 as most promising due to its highly immunogenicity during early infection, expressed protein can be recognized by Trichinella early infection sera and the native Ts14-3-3 expression in both adult and larval stages.

Keywords: Trichinella spiralis, Adult worm, Mass spectrometry, Immunoproteomics, Diagnosis

\footnotetext{
* Correspondence: zhuxping@ccmu.edu.cn

Department of Parasitology, School of Basic Medical Sciences, Capital

Medical University, Beijing, China
}

\section{() Biomed Central}

(c) 2015 Yang et al.; licensee BioMed Central. This is an Open Access article distributed under the terms of the Creative Commons Attribution License (http://creativecommons.org/licenses/by/4.0), which permits unrestricted use, distribution, and reproduction in any medium, provided the original work is properly credited. The Creative Commons Public Domain Dedication waiver (http://creativecommons.org/publicdomain/zero/1.0/) applies to the data made available in this article, unless otherwise stated. 


\section{Background}

Trichinellosis, which is caused by infection with the nematode Trichinella spiralis remains an important food-borne parasitic zoonosis worldwide. It not only causes a public health hazard but also represents an economic problem in porcine animal production and food safety [1,2]. Human trichinellosis is primarily caused by ingesting the raw or undercooked meat of pigs and other animals containing $T$. spiralis larvae [3]. The disease affects as many as 11 million people and is regarded as a re-emerging disease [4]. From 2005 to 2009 in China, 15 outbreaks of human trichinellosis were reported, with 1387 cases and four deaths [5]. T. spiralis is a tissuedwelling parasitic nematode, and its life cycle is completed in a single host, including all stages of the adult worm (Ad), newborn larvae (NBL) and muscle larvae (ML). After ingestion, muscle larvae are released from the capsules and develop into sexually mature adult worms in the intestine. Each female worm can produce 500-1000 NBL in a period of 5-10 days. Then, the NBL migrate through the lymphatic system and the general circulatory system. Subsequently, the parasites develop into infective muscle larvae encapsulated in the host skeletal muscles [6]. During all developmental stages, $T$. spiralis expresses many immunodominant antigens that elicit a protective immune response, as well as antigens useful for the serodiagnosis of trichinellosis $[7,8]$.

Because trichinellosis manifests as nonspecific signs and symptoms, the clinical diagnosis of this disease is difficult [9]. Currently, the diagnosis of trichinellosis relies on detection of the larvae in a muscle biopsy or highly specific immunodiagnostic tests. The immunological tests current available use excretory-secretory products (ES) secreted by the living larvae as antigens to detect antibodies in the sera of infected individuals. However, testing is not widely available because of the limited availability of antigens produced by $T$. spiralis larvae. These tests are also not sensitive for the detection of the early stage of infection and may cross-react with other parasites $[10,11]$. Another weakness of serologic methods using ES products as antigens is the high rate of false negative results, even with a combination of ELISA and Western blot, which may increase the detection sensitivity $[10,11]$. Anti-helminthic drugs are more effective against the adult worms remaining in the intestine during early infection than the encapsulated muscle larvae. After the newborn larvae are released by the adult worm, the NBL migrate to the muscle tissue to be encapsulated that are more resistant to anthelmintic therapy and cause greater pathology; therefore, it is critical to identify and diagnose early infection for timely treatment $[9,12]$. The antigens from the early stage of infection, such as adult worms and newborn larvae, are immunogenic and induce immune responses in an infected host and may be used for early immunodiagnosis [7]. Although previous studies showed that some antigens derived from newborn larvae are recognized by $T$. spiralis-infected animal sera or have potential as vaccine antigens $[13,14]$, these antigens have not shown satisfactory results for detecting early infections or vaccine development. Therefore, it is necessary to identify sensitive and specific novel antigens derived from adult worms or newborn larvae to detect early infection by $T$. spiralis to achieve better therapeutic effects.

Two-dimensional electrophoresis (2-DE), combined with mass spectrometry (MS) is an effective approach for high resolution analysis of complex groups of proteins [15]. Combining these techniques with Western blot using a specific antibody allows us to identify antigens that induce host immune responses during infection and could therefore be used for immunodiagnosis and/or vaccine development. This immunoproteomics tool provides information on both the characteristics of immunogenic proteins and the serological response directed against parasites, such as Schistosoma japonicum [16], Toxoplamsma gondii [17], Ascaris lumbricoides [18] and Taenia solium [19]. In fact, several excretorysecretory (ES) proteins and surface proteins from $T$. spiralis muscle larvae were identified by using this immunoproteomic tool [20-22]. These results suggest that proteins, such as serine protease, $\mathrm{p} 43$ glycoprotein and 5 '-nucleotidase, are potential diagnostic antigens and the targets for vaccines in host-parasite interactions. However, these antigens are derived from muscle larvae and may not be suitable for the early diagnosis of Trichinella infection.

In this study, to identify antigens recognized by the host immune system during early enteric infection, $T$. spiralis adult worm extracts were separated by $2-\mathrm{DE}$ and recognized using sera from pigs and mice infected with T. spiralis for 7 days. The primary immunoreactive spots recognized using the early infection sera were characterized by MALDI-TOF/TOF-MS analyses in combination with bioinformatics. The antigens recognized by the sera during this early stage may be used to immunodiagnose the early infection by $T$. spiralis. The results of this study will facilitate the selection of antigens as reagents for early serological diagnosis and possibly vaccine development.

\section{Methods}

\section{Animals}

Experimental animals (mice and pigs) were purchased from the Laboratory Animal Services Center of Capital Medical University (Beijing, China). Experimental procedures for $T$. spiralis infection were reviewed and approved by the Capital Medical University Animal Care and Use Committee and were consistent with the NIH Guide for the Care and Use of Laboratory Animals. 


\section{Maintenance and collection of $T$. spiralis worms and protein sample preparation}

The T. spiralis ISS 533 strain used in this study was maintained in female ICR mice in our laboratory, and $T$. spiralis muscle larvae were recovered from the muscles of infected mice with a standard pepsin/hydrochloric acid digestion method [23]. The adult worms were collected from the small intestine of experimentally infected Wistar rats at 4 days after experimental infection.

The collected adult worms were washed several times in PBS and then homogenized in lysis buffer containing $7 \mathrm{M}$ urea, $2 \mathrm{M}$ thiourea, 4\% CHAPS, $65 \mathrm{mM}$ Tris, 2\% DTT, and 1\% Bio-Lyte (pH3-10). The adult worm lysates were centrifuged at $20,000 \times \mathrm{g}$ at $4^{\circ} \mathrm{C}$ for $60 \mathrm{~min}$ and the supernatant was collected as adult extracts. The total protein concentration was determined using a 2D Quant kit (GE Healthcare, USA) and stored at $-80^{\circ} \mathrm{C}$ until use for proteomic analysis.

\section{Collection and preparation of $T$. spiralis infected animal sera}

T. spiralis infected pig sera were collected from 4 pigs orally infected with $20,000 \mathrm{~T}$. spiralis muscle larvae each for 7 days and pooled. The infected mouse sera were obtained from $10 \mathrm{BALB} / \mathrm{c}$ mice orally infected each with 500 T. spiralis muscle larvae for 7 days. Uninfected sera from normal pigs and mice were collected as negative controls.

\section{Two-dimensional polyacrylamide gel electrophoresis (2-DE)}

Approximately, $400 \mu \mathrm{g}$ of $T$. spiralis adult extracts were used for each 2-DE analysis. The worm extracts with bromophenol blue were loaded into $17 \mathrm{~cm} \mathrm{pH} \mathrm{3-10}$ immobilized pH gradient (IPG) strips (Bio-Rad, USA) and separated by isoelectric focusing (IEF) using a Protean IEF Cell (Bio-Rad, USA). IEF was performed at $20^{\circ} \mathrm{C}$ with rehydration at $20^{\circ} \mathrm{C}$ for $12 \mathrm{~h}$, followed by isoelectric focusing according to the manufacturer's instructions. After isoelectric focusing, the IEF strips were equilibrated for $15 \mathrm{~min}$ in a reducing buffer (6 M urea, 2\% SDS, $0.375 \mathrm{M}$ Tris- $\mathrm{HCl} \mathrm{pH} 8.8,20 \%$ glycerol, and 2\% DTT), followed by $15 \mathrm{~min}$ in an alkylation buffer (6 M urea, 2\% SDS, 0.375 M Tris- $\mathrm{HCl}$, pH8.8, 20\% glycerol, and $2.5 \%$ iodoacetamide). For the second dimension, the equilibrated IPG strips were placed on 12\% SDS-PAGE and run at $15 \mathrm{~mA} / \mathrm{gel}$ for $30 \mathrm{~min}$. The gels were either stained with Coomassie Blue R-350 or transferred to a PVDF membrane for Western blot. Three gels were run for the adult worm extracts under the same conditions.

\section{Western blot analysis}

The separated protein spots from the 2-DE gels were transformed onto PVDF membranes (Millipore, USA) using a Trans-blot semi-dry Transfer Cell TM (Bio-RAD, USA) for $90 \mathrm{~min}$ at $18 \mathrm{~V}$. The membranes were blocked with $5 \%$ skimmed milk in PBS, $\mathrm{pH} 7.4$ for $2 \mathrm{~h}$ at room temperature and then incubated with either T. spiralis infected swine pooled sera or infected mouse sera diluted 1:1 00 in PBS, pH7.4, with 0.05\% Tween 20 (PBST). After 3 washes in PBST, the membranes were incubated with the horseradish peroxidase-conjugated rabbit anti-swine IgG or goat anti-mouse IgG (Sigma, USA). Reproducibility of the immune recognition was verified by repeating the immunoblot at least three times. The sera collected from normal swine or mice were used as controls. The PDQuest $^{\mathrm{TM}}$ 2-D Analysis Software (Bio-RAD, USA) was used for matching and analysis of the antigenic protein spots on the 2-D gels.

\section{In-gel tryptic digestion}

Only those spots recognized by the infection sera from both the pigs and mice were selected for further study. Following the selection of spots of interest by matching with the immunoblot image, the protein spots on the Coomassie Blue-stained gels were carefully excised. The excised gel

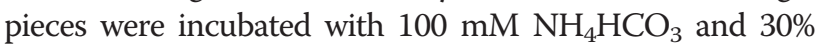
$\mathrm{CAN}$ in the dark, washed with $100 \mathrm{mM} \mathrm{NH} \mathrm{NCO}_{3}$ and dried. Then, the gel species were further rehydrated in digestion buffer containing trypsin (Promega, USA) and incubated at $37^{\circ} \mathrm{C}$ overnight. The trypsin-digested peptides were subsequently extracted with $100 \mu \mathrm{l}$ of $60 \% \mathrm{ACN} / 0.1 \%$ trifluoroacrtic acid (TFA) and prepared for MALDI-TOF/ TOF-MS analysis.

\section{Protein identification using MALDI-TOF /TOF-MS analysis}

The resulting peptides from the above extraction were analyzed on an Applied Biosystem Sciex 4800 mass spectrometer (Applied Biosystems, USA). The MS spectra were recorded in reflector mode in a mass range from 800 to 4000 . The peptide mass fingerprints (PMFS) were obtained. The peaks with the highest mass intensities were selected for MS/MS for protein identification. Each peptide assignment was also manually verified. The PMFS and MS/MS data were searched from the NCBI and SwissProt databases of the existing T. spiralis genome or ESTs using MASCOT version 2.2 (Matrix Science, LTD). Protein identification was considered accurate when the confidence scores $>95 \%$ and the MASCOT score was $>50$. The identified proteins were categorized by their protein sequences according to the information obtained from the InterProsan software. The outputs were subjected to analysis by the GO categories using the Web Gene Ontology Annotation Plotting (WEGO, http://wego.genomics.org.cn/ cgi-bin/wego/index.pl). 
Expression and immunological test of recombinant Ts143-3 (rTs14-3-3)

DNA coding for the full length Ts14-3-3 was amplified from total cDNA reverse-transcribed from total $T$. spiralis adult RNA using primers designed according to Ts14-3-3 sequence (GenBank accession no. XM_00 3378886) (the forward primer: 5 '-CGGGATCCATGA CCGAAAAGGAAGACAT-3' and the reverse primer: 5' -CGGAATTCCTGCCCAGCGGCTGTATCTT-3').

The amplified DNA products were cloned into the expression vector pET-28a (+) (Novagen, Germany) using BamHI and XhoI sites. The recombinant pET28a $(+) / T s 14-3-3$ plasmids were transformed into the E. coli BL21. The recombinant protein (rTs14-3-3) was induced with $1 \mathrm{mM}$ IPTG and the expressed soluble recombinant Ts14-3-3 was purified using His-Bind Purification Kit (Novagen, USA).

Following SDS-PAGE, the rTs14-3-3 was transferred onto nitrocellulose membrane. The membrane was incubated with the same $T$. spiralis-infected swine or mice sera used for identifying the immunogenic antigens described above. The recombinant Ts14-3-3 was used to immunize mouse to obtain antiserum in order to detect the expression of native $T s 14-3-3$ in adult worm and muscle larvae stages of $T$. spiralis.

\section{Results}

\section{2-DE analysis of $T$. spiralis adult extracts}

The somatic proteins of the $T$. spiralis adult extracts were separated on a 2-DE gel, and the protein spots were visualized following Coomassie R-350 staining (Figure 1A). Image analysis revealed more than 300 spots stained on the gel, the majority of which migrated between $\mathrm{pH} 4$ and 10 over a broad range of molecular masses between 10$150 \mathrm{kDa}$.

\section{Immunoreactive antigens recognized by early infected swine and mouse sera}

The PDQuest software allowed us to overlap shared spots between the 2 species, swine and mouse, based on the same MWs and isoelectric points. As shown in Figure $1 \mathrm{~B}$ and Figure $1 \mathrm{C}$, there were more than sixty protein spots recognized by sera from both swine and mice infected with $T$. spiralis for 7 days, with molecular weights ranging from $20 \mathrm{kDa}$ to $180 \mathrm{kDa}$, and pI values from 3-10. Most of the recognized antigens were between $30 \mathrm{kDa}$ to $150 \mathrm{kDa}$, with pI values between 4 and 9 . The spots and their corresponding proteins on the gel were labeled individually with the same number. No proteins reacted to normal swine or mouse serum (Figure 1D).

Identification of protein spots by MALDI-TOF MS analysis The immunoblot and the Coomassie Blue stained gel were aligned and matched with the PDQuest ${ }^{\mathrm{Tm}}$ 2-D Analysis
Software. Sixty-four of the positive spots recognized by swine and mice sera infected with $T$. spiralis for 7 days were matched and located on the Coomassie blue stained gel, and then excised for in-gel tryptic digestion. The digested peptides were then subjected to MALDI-TOF/ TOF-MS analysis. The proteins listed in the table are the highest ranked candidates that were unambiguously identified in the MASCOT search (Table 1) with molecular weights listed from high to low. A total of 55 immunoreactive proteins were identified by peptide mass fingerprinting. Nine spots selected for MS analysis did not generate any MS data. Several proteins, such as the intermediate filament protein, actin-5c, 14-3-3, inorganic pyrophosphatase, putative thioredoxin, and serine protease inhibitor were identified in several spots next to each other. Actin-5c was identified in spots 19, 20, 21, and 22. The 14-3-3 protein was found in spots 60 and 61. Putative thioredoxin was identified in spots 42, 51 and 52 . Spots 56, 57 and 59 were the serine protease inhibitor kazal-type 4. As a consequence, a total of 40 distinct immunoreactive proteins were identified. Notably, several house-keeping genes were identified, such as actin and intermediate filament protein. Several proteins were involved in bioprocessing, metabolism and signaling pathways, such as cysteine proteases, inorganic pyrophosphatase protein-tyrosine phosphatase, heat shock protein and developmental-regulated GTP-binding protein.

\section{Distribution of the identified protein spots}

The molecular weight (MW) and isoelectric point (pI) of the identified proteins were analyzed (Figure 2A). The MW of 55 proteins was ranged from 12.32 to $93.66 \mathrm{kDa}$. Twenty-eight of 55 (50.9\%) proteins ranged from 30 to $50 \mathrm{kDa}$. The pI was between 4.83 and 9.04 , and 29 of 55 (52.7\%) proteins were in the range of pI $5 \sim 6$ (Figure $2 \mathrm{~B}$ ). The two-dimensional distribution of the 55 identified proteins is shown in Figure 2C.

\section{Gene ontology analysis}

To further understand the functions of these identified immunoreactive proteins, the InterPro database was searched based on the BLASTP results. A total of 40 proteins, not including the 15 repeated protein spots, were categorized by cellular component, molecular function, and biological process using WEGO. The primary molecular functions were catalytic activity (GO: 0003824) and binding (GO: 0005488). These proteins were classified into eight categories related to their biological process as follows: biological regulation, cellular component organization, cellular process, establishment localization, metabolic process, pigmentation, and response to stimulus. For the biological process function, a large proportion was metabolic process (GO: 


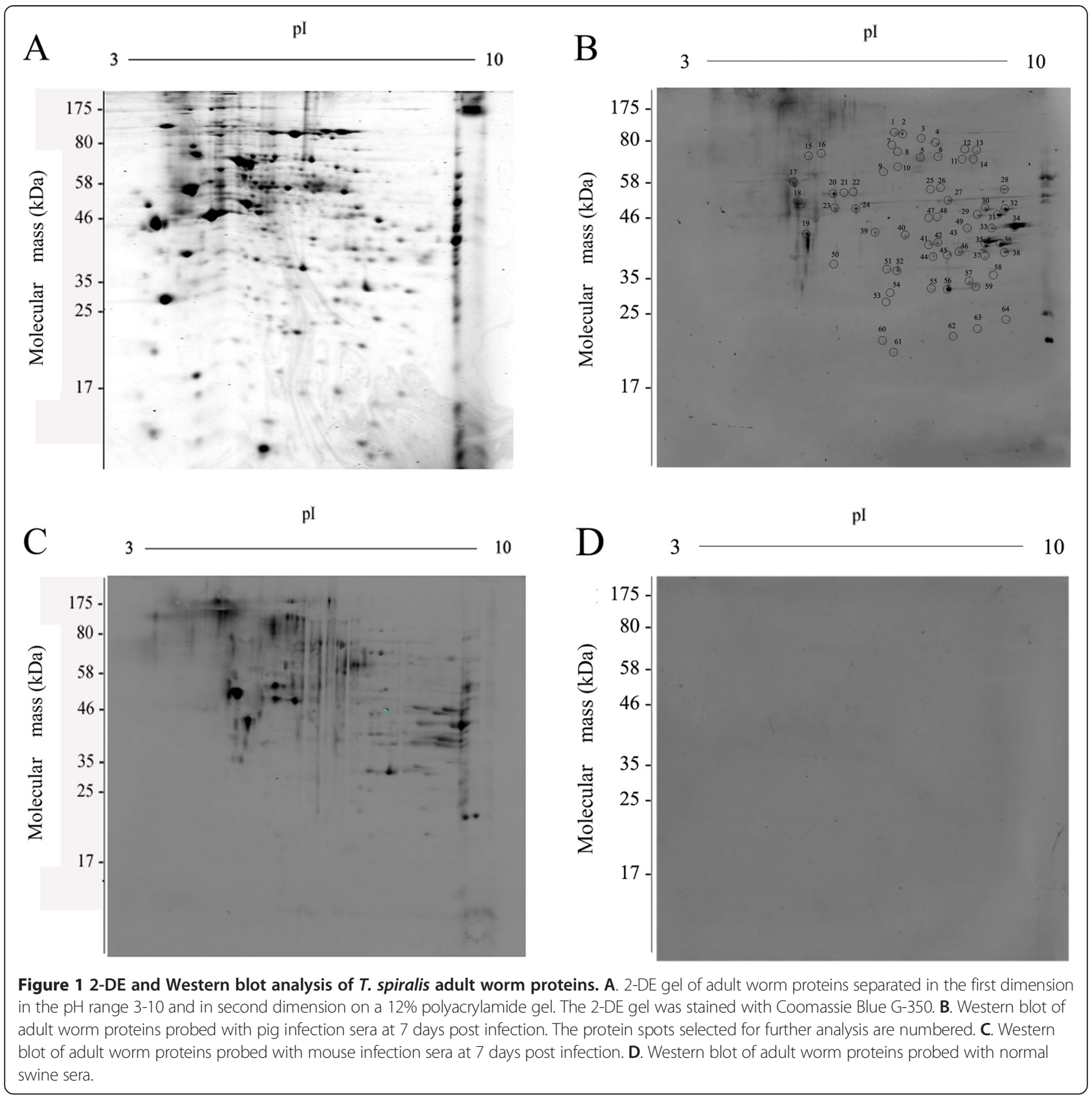

0008152) and cellular process (GO: 0009987). These results are shown in Figure 3.

\section{Expression feasibility of rTs14-3-3 and its recognition by infected sera}

To validate the potential of Ts14-3-3 as vaccine or diagnostic antigen, the Ts14-3-3 was successfully cloned and expressed in E. coli BL21 as soluble recombinant protein. As shown in Figure 4A, the recombinant protein (rTs14-3-3) was highly induced in BL21 in soluble and insoluble fractions The molecular mass of the rTs14-3-3 (with the histidine tag) was approximately $30 \mathrm{kDa}$, which corresponded well to the predicted size of the gene product. The rTs14-3-3 was easily purified with Ni-affinity chromatography. The purified $\mathrm{r} T s 14-3-3$ was able to be strongly recognized by the same $T$. spiralis-infected swine and mouse sera used for identifying the immunogenic antigens by immunoproteomic approach, but not by normal swine and mice sera (Figure 4B). The rTs14-3-3 was recognized not only by the early infected swine sera ( $7 \mathrm{dpi}$ ) but also by the sera from swine infected with $T$. spiralis for up to 28 days (Figure 4C). The expression of native Ts14-3-3 
Table 1 Identification of $T$. spiralis adult worm proteins recognized by pig and mouse infection sera at 7 DPI

\begin{tabular}{|c|c|c|c|c|c|c|c|c|}
\hline Spot no. & Protein name & NCBI ID & $\mathrm{pl}$ & $\begin{array}{l}\text { MW } \\
(\mathrm{kDa})\end{array}$ & $\begin{array}{l}\text { Protein } \\
\text { score }\end{array}$ & $\begin{array}{l}\text { Protein score } \\
\text { C.I.\% }\end{array}$ & $\begin{array}{l}\text { Coverage } \\
(\%)\end{array}$ & $\begin{array}{l}\text { No. matched } \\
\text { peptides }\end{array}$ \\
\hline 1 & $\begin{array}{l}\text { intermediate filament } \\
\text { protein ifa-1 }\end{array}$ & gi|316973417 & 5.96 & 73.218 & 816 & 100 & 62 & 34 \\
\hline 2 & 6-phosphofructokinase & gi|316973417 & 7.97 & 93.66 & 93 & 100 & 15 & 11 \\
\hline 3 & $\begin{array}{l}\text { heat shock protein } 70 \\
\text { (Trichinella britovi) }\end{array}$ & gi|2104672 & 5.77 & 71.86 & 33 & 99.5 & 18 & 11 \\
\hline 4 & $\begin{array}{l}\text { MAP/microtubule affinity- } \\
\text { regulating kinase } 3\end{array}$ & gi|316978564 & 9.25 & 78.23 & 115 & 100 & 18 & 11 \\
\hline 5 & chaperone protein DnaK & gi|316972817 & 5.43 & 73.47 & 494 & 100 & 36 & 22 \\
\hline 6 & $\begin{array}{l}32 \mathrm{kDa} \text { beta-galactoside- } \\
\text { binding lectin (Galectin-1) }\end{array}$ & gi|316970057 & 9.04 & 55 & 85 & 100 & 17 & 7 \\
\hline 7 & $\begin{array}{l}\text { F-box/WD repeat-containing } \\
\text { protein sel-10 }\end{array}$ & gi|316975364 & 6.29 & 67.25 & 67 & 100 & 19 & 9 \\
\hline 8 & HAD-superfamily hydrolase & gi|316976388 & 7.8 & 66.01 & 56 & 98.7 & 10 & 6 \\
\hline 9 & cysteine protease ATG4B & gi|316968242 & 5.79 & 47.54 & 68 & 100 & 20 & 6 \\
\hline 10 & $\begin{array}{l}\text { developmentally-regulated } \\
\text { GTP-binding protein } 1\end{array}$ & gi|316965924 & 8.97 & 48.51 & 52 & 99.6 & 20 & 7 \\
\hline 11 & $\begin{array}{l}\text { dolichyl-diphosphooligosaccharide-- } \\
\text { protein glycosyltransferase subunitSTT3A }\end{array}$ & gi|316976331 & 8.85 & 62.448 & 62 & 97.996 & 25 & 11 \\
\hline 12 & HAD-superfamily hydrolase & gi|316976388 & 7.8 & 66.01 & 56 & 98.7 & 10 & 6 \\
\hline 13 & $\begin{array}{l}\text { putative glutaredoxin-like } \\
\text { protein }\end{array}$ & gi|316970937 & 6.21 & 91.79 & & & & 13 \\
\hline 14 & MYND finger protein & gi|316977375 & 8.8 & 56.83 & 64 & 100 & 12 & 5 \\
\hline 15 & $\begin{array}{l}\text { intermediate filament protein } \\
\text { ifa-1 }\end{array}$ & gi|316973417 & 5.96 & 73.21 & 478 & 99.9 & 51 & 31 \\
\hline 16 & acyl-protein thioesterase & gi|316970759 & 5.02 & 55.8 & 108 & 100 & 13 & 5 \\
\hline 17 & $\begin{array}{l}\text { putative stress-induced- } \\
\text { phosphoprotein } 1\end{array}$ & gi|316977783 & 6.01 & 58.16 & 93 & 100 & 22 & 9 \\
\hline 18 & 7 transmembrane receptor & gi|316965614 & 5.82 & 41.87 & 89 & 100 & 38 & 14 \\
\hline 19 & Actin-5c & gi|316970244 & 5.3 & 42.21 & 280 & 100 & 36 & 10 \\
\hline 20 & Actin-5c & gi|316970244 & 5.3 & 42.21 & 422 & 100 & 34 & 9 \\
\hline 21 & Actin-5c & gi|316970244 & 5.3 & 42.21 & 133 & 100 & 17 & 5 \\
\hline 22 & Actin-5c & gi|316970244 & 5.3 & 42.21 & 133 & 100 & 17 & 5 \\
\hline 23 & inorganic pyrophosphatase & gi|316967781 & 5.76 & 41.796 & 96 & 100 & 12 & 4 \\
\hline 24 & inorganic pyrophosphatase & gi|316967781 & 5.76 & 41.796 & 96 & 100 & 12 & 4 \\
\hline 25 & No identified & & & & & & & \\
\hline 26 & No identified & & & & & & & \\
\hline 27 & adenosine deaminase & gi|47934208 & 5.93 & 39.787 & 61 & 97.4 & 13 & 4 \\
\hline 28 & $\begin{array}{l}\text { putative LIM and SH3 domain } \\
\text { protein }\end{array}$ & gi|316973491 & 9.47 & 33.96 & 63 & 98.7 & 33 & 9 \\
\hline 29 & hypothetical protein Tsp_11860 & gi|316969203 & 8.09 & 39.25 & 65 & 98.2 & 25 & 8 \\
\hline 30 & hypothetical protein Tsp_11860 & gi|316969203 & 8.09 & 39.25 & 68 & 97.8 & 25 & 8 \\
\hline 31 & ubiquitin-conjugating enzyme E2 1 & gi|316968002 & 7.07 & 41.31 & 65 & 100 & 19 & 8 \\
\hline 32 & phosphomannomutase 2 & gi|316975006 & 5.76 & 31.86 & 379 & 100 & 43 & 12 \\
\hline 33 & zinc metallo protein & gi|316965635 & 5.93 & 32.23 & 73 & 100 & 23 & 6 \\
\hline 34 & hypothetical protein Tsp_11358 & gi|316966928 & 9.51 & 34.91 & 82 & 100 & 34 & 8 \\
\hline 35 & $\begin{array}{l}\text { Tas retrotransposon peptidase A16 } \\
\text { superfamily protein }\end{array}$ & gi|316959639 & 8.6 & 37.73 & 64 & 99.8 & 23 & 9 \\
\hline 36 & putative trypsin & gi|316978020 & 8.53 & 39.6 & 89 & 100 & 23 & 7 \\
\hline
\end{tabular}


Table 1 Identification of $T$. spiralis adult worm proteins recognized by pig and mouse infection sera at 7 DPI (Continued)

\begin{tabular}{|c|c|c|c|c|c|c|c|c|}
\hline 37 & No identified & & & & & & & \\
\hline 38 & protein-tyrosine phosphatase & gi|316967260 & 5.92 & 25.75 & 94 & 100 & 21 & 5 \\
\hline 39 & putative nudix hydrolase 6 & gi|339244291 & 5.21 & 32.98 & 63 & 98.44 & 15 & 4 \\
\hline 40 & Actin-depolymerizing factor 2 & gi|316972221 & 6.37 & 40.828 & 123 & 100 & 10 & 4 \\
\hline 41 & $26 S$ protease regulatory subunit $6 \mathrm{~B}$ & gi|316968151 & 5.47 & 39 & 88 & 100 & 19 & 5 \\
\hline 42 & putative thioredoxin & gi|316967722 & 5.56 & 36.88 & 217 & 100 & 34 & 8 \\
\hline 43 & 265 protease regulatory subunit 7 & gi|316970971 & 5.67 & 49 & 97 & 100 & 22 & 9 \\
\hline 44 & vacuolar proton pump subunit E & gi|316974496 & 5.8 & 26.14 & 163 & 100 & 30 & 5 \\
\hline 45 & inositol monophosphatase & gi|316978221 & 5.65 & 23.35 & 185 & 100 & 38 & 5 \\
\hline 46 & No identified & & & & & & & \\
\hline 47 & hypothetical protein Tsp_11860 & gi|316969203 & 8.09 & 39.25 & & & 25 & 8 \\
\hline 49 & No identified & & & & & & & \\
\hline 50 & No identified & & & & & & & \\
\hline 51 & putative thioredoxin & gi|316967722 & 5.56 & 36.88 & 217 & 100 & 34 & 8 \\
\hline 52 & putative thioredoxin & gi|316967722 & 5.56 & 36.88 & 217 & 100 & 34 & 8 \\
\hline 53 & No identified & & & & & & & \\
\hline 54 & tumor protein D52 & gi|316971259 & 5.98 & 16.889 & 84 & 97.9 & 59 & 7 \\
\hline 55 & No identified & & & & & & & \\
\hline 56 & serine protease inhibitor Kazal-type 4 & gi|316969591 & 8.56 & 24.89 & 72 & 99.875 & 27 & 4 \\
\hline 57 & serine protease inhibitor Kazal-type 4 & gi|316969591 & 8.56 & 24.89 & 72 & 99.875 & 27 & 4 \\
\hline 58 & No identified & & & & & & & \\
\hline 59 & serine protease inhibitor Kazal-type 4 & gi|316969591 & 8.56 & 24.89 & 72 & 99.875 & 27 & 4 \\
\hline 61 & 14-3-3 protein & gi|257219670 & 4.83 & 28.29 & 74 & 99.855 & 24 & 6 \\
\hline 62 & tumor protein D52 & gi|316971259 & 5.98 & 16.889 & 84 & 97.9 & 59 & 7 \\
\hline 63 & translation initiation factor elF-5A & gi|316973471 & 5.17 & 12.32 & 113 & 100 & 57 & 4 \\
\hline 64 & tumor protein D52 & gi|316971259 & 5.98 & 16.889 & 84 & 97.9 & 59 & 7 \\
\hline
\end{tabular}

was detected in both stages of $T$. spiralis by using mouse antisera against rTs14-3-3 (Figure 4D).

\section{Discussion}

In recent years, trichinellosis has become an emerging and re-emerging parasitic diseases and the severity of trichinellosis in human ranges from subclinical to fatal [24]. Early diagnosis of the infection is critical for the timely and effective treatment of trichinellosis because anthelmintic drugs are much more effective against adult worms in the intestine than to the encapsulated larvae in the muscle $[9,12]$. Therefore, it is important to identify antigens recognized by the host immune system during the early infection stage. These immunodominant antigens can be developed as biomarkers for the early diagnosis of trichinellosis or even as vaccine candidates to better control this food-borne zoonotic disease.
Although a number of Trichinella antigens, such as TSL-1, serine protease and histidine-tailed metalloprotein, have been identified as immunodominant antigens recognized by the host immune system during natural infection $[8,25,26]$, these antigens do not meet the requirements for the early diagnosis of infection. Some somatic antigens from adult $T$. spiralis worms were recognized by Trichinella early or late infection sera from pigs by immunoscreening the adult worm cDNA library [27]. Therefore, it is possible to identify and develop these immunodominant antigens from adult worm as immunological reagents for the early diagnosis of Trichinella infection because the adult stage only exists during the early stage of infection.

In this study, a novel immunoproteomics approach was used to identify potential immunogens for the early diagnosis of trichinellosis or to develop an effective vaccine. The soluble extracts from $T$. spiralis adult worms 

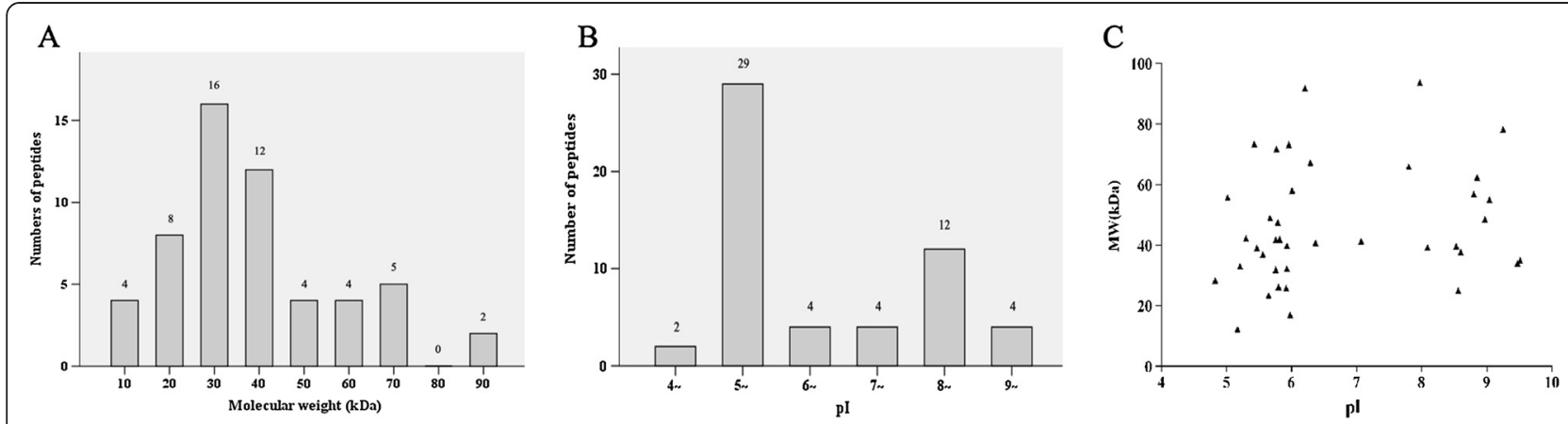

Figure 2 Distributions of T. spiralis adult worm proteins spots recognized by both pig and mouse anti-T. spiralis sera at 7 DPI. (A) Distributions of molecular weight (MW) for T. spiralis adult worm proteins recognized by both pig and mouse anti-T. spiralis sera at 7 DPI. (B) Distributions of isoelectric point (pl) for T. spiralis adult worm protein spots recognized by both pig and mouse anti-T. spiralis sera at 7 DPI. (C) The two-dimensional distribution of $T$. spiralis adult worm protein spots recognized by both pig and mouse anti-T. spiralis sera at 7 DPI.

were separated by 2-DE and detected with early infection sera from swine or mice infected with $T$. spiralis for only 7 days. During this period of infection, Trichinella infective larvae develop only into adult worms in the intestine of the infected host; therefore, the antigens from the adult worms that elicit an early immune response in infected animals may be used as potential target antigens for early diagnosis and/or vaccines against trichinellosis.

More than $60 T$. spiralis adult worm proteins were recognized by the pooled early infection sera from infected pigs and mice, and 55 of these proteins were identified by MALDI-TOF/TOF-MS. The MW of the identified antigens ranged from $12.3 \mathrm{kDa}$ to $93.7 \mathrm{kDa}$, and the $\mathrm{pI}$ ranged from $\mathrm{pH} 5.0$ and 9.5. The fifty-five identified antigens represent 40 different proteins. Several antigens had more than one spot with different pIs, such as intermediate filament protein, actin-5c, 14-3-3, inorganic pyrophosphatase, putative thioredoxin, and serine protease inhibitor. It is possible that these antigens have more than one isoform with different post-translation modifications or binding to different co-factors that change their pI or molecular weight. Remarkably, these proteins are involved in a wide range of biological functions, such as biological regulation, cellular process, metabolic process, and localization.

Among the potential immunogens in present study, several structural proteins, including cytoskeleton and muscle proteins, such as actin-5c was also identified. Studies indicated that actin is related to the invasion of worm into the intestinal epithelial cells, indicating this protein may be involved in the early survival of the parasites within the host [28]. Mice infected with Echinostoma caproni, an intestinal trematode, produce early

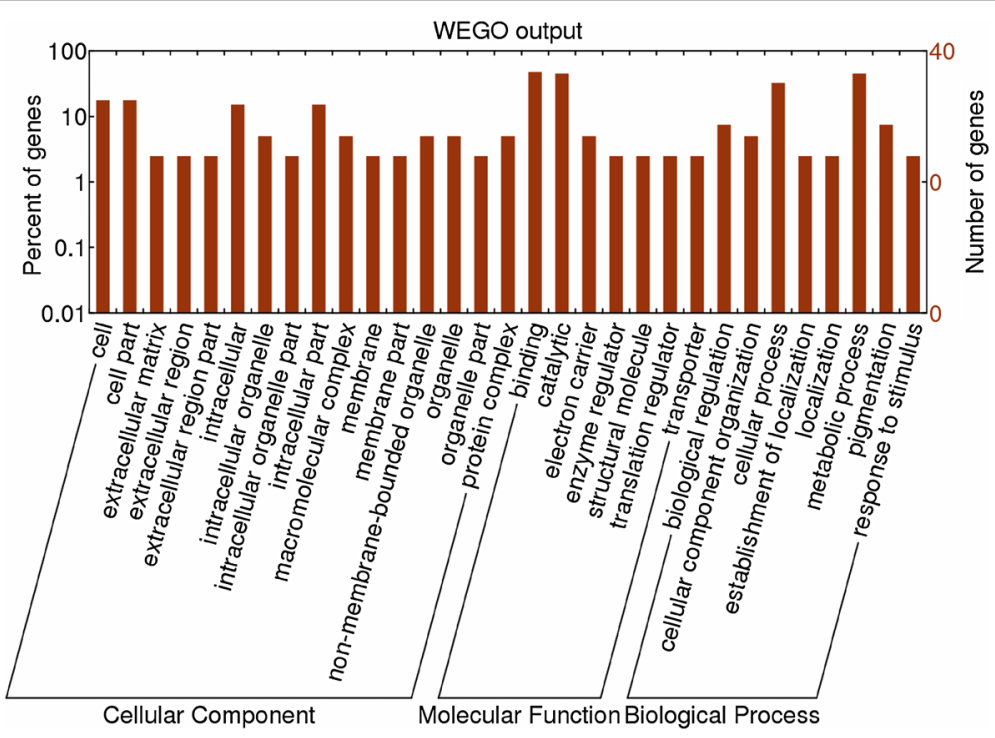

Figure 3 GO categories of $T$. spiralis immunoreactive adult worm proteins. The proteins were classified into cellular component, molecular function and biological process by WEGO according to their GO signatures. 

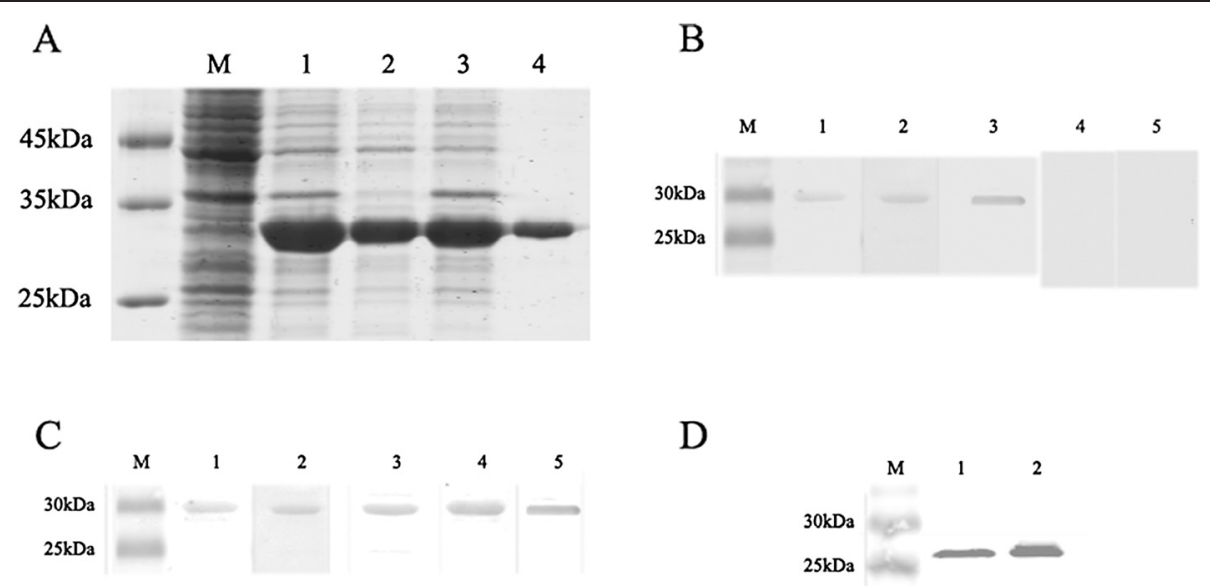

Figure 4 SDS-PAGE and Western blot analysis of rTs14-3-3 expressed in E. coli BL21. (A) Bacterial lysates or purified recombinant protein were analyzed by SDS-PAGE and stained with Coomassie blue. Lane M, protein marker; lane 1, uninduced E. coli lysate; lane 2, IPTG-induced E. coli lysate; lane 3, insoluble fraction of induced E. coli lysate ; lane 4, soluble fraction of induced E. coli lysate ; lane 5, rTs 14-3-3 purified by Ni-affinity chromatography. (B) Western blot analysis of rTs14-3-3. The rTs14-3-3 was transferred on individual lane and recognized by T. spiralis infected swine sera at $7 \mathrm{dpi}$ (lane 1); T. spiralis infected mouse sera at $7 \mathrm{dpi}$ (lane 2) and anti-His monoclonal antibody (lane 4). (C). The rTs 14-3-3 was recognized by sera of swine infected with $T$. spiralis for 7 days (lane 1); 14 days (lane 2); 21 days (lane 3) and 28 days ( lane 4) or by anti-His antibody as control (lane 5). D. Western blot analysis of native Ts14-3-3 in adult extracts (lane 1) and in muscle larval extracts (lane 2) of T. spiralis by antibody against rTs-14-3-3.

immune responses to actin, suggesting that this protein is exposed early to the host and may be of importance in the establishment of parasitism [29].

Heat shock proteins (HSPs) are traditionally considered a highly immunogenic and conserved family of proteins. These proteins were identified as potential vaccine candidate antigens and may also function as immunological modulators of immune responses [30]. Of these, HSP70 is a major target of immune responses of the host to infections by helminths and protozoan parasites $[31,32]$. Previous studies indicated that SmHSP70 elicited an early humoral immune response and may be a good target for the immunodiagnosis of schistosomiasis [33]. HSP70 in Echinostoma caproni also induced a strong early immune response in mice [29]. Moreover, our previous study indicated that $T s$-Hsp70 from adult $T$. spiralis is highly immunogenic and may be a good vaccine candidate $[34,35]$. In this study, Ts-HSP70 was recognized by early infection sera, indicating that this protein has potential for the early diagnosis of trichinellosis.

Another interesting protein recognized by early infected sera in this study is cysteine protease. This protease is a key molecule in host-parasite interactions, which has gained significant attention as a target for chemotherapy or immunoprophylaxis [36]. Vaccination with cysteine protease coding DNAs induced significant protection against several helminth and protozoan infections by reducing the parasite burden or fecal egg count and reducing egg viability [37]. In addition, many cysteine proteases can be used for the immunodiagnosis of parasitic diseases with good sensitivity and specificity [38,39]. Recognition of the cysteine protease by early $T$. spiralis infection sera in this study suggests that $T$. spiralis cysteine protease is not only a good target for vaccine but also a promising target for immunodiagnostic antigen.

Of the immunogens identified in the present study, the 14-3-3 protein is of particular interest. There were two protein spots that matched the 14-3-3 protein of T. spirali, which indicates that the 14-3-3 protein was a strong immunogenic antigen during the early infection. The 14-3-3 proteins, a series of abundant acidic proteins which belong to a family of conserved regulatory molecules, play key roles in several eukaryotic biochemical processes, such as signal transduction, transport, regulation, cell differentiation and cell survival, and have been identified in several helminth parasites [40,41]. Studies indicated that this protein could be used for routine immunodiagnosis and serological epidemiological surveys as well for helminthic diseases with high sensitivity and specificity $[42,43]$. In addition, for parasites, such as $S$. mansoni and E. granulosus, the 14-3-3 proteins can induce humoral and cellular immune responses and have been tested as potential vaccine targets [44,45]. Therefore, it intrigues our interest to evaluate Ts14-3-3 identified in this study as a reagent for the early serologic diagnosis for trichinellosis or even for the target of vaccine against Trichnelle infection. Primary expression assay demonstrated that Ts14-3-3 is feasible to be expressed as soluble recombinant protein in E. coli and the purified recombinant Ts14-3-3 from induced bacterial lysates was able to be recognized not only by the early $T$. spiralis-infected sera from swine and mice ( $7 \mathrm{dpi})$, but also by sera of swine infected for up to 28 days. In addition, this antigen 
exists in both adult and muscle larvae stages, indicating this Ts14-3-3 can be used not only for early diagnosis but also for detecting whole period of infection. These results further confirm that Ts14-3-3 is an immunodominant antigen recognized by $T$. spiralis infected sera and could be a good target for early immunodiagnosis of trichinellosis. The sensitivity and specificity of recombinant $T s 14-3-3$ as an antigen for serological diagnosis of Trichinella infection is under investigation by testing the defined sera from patients with trichinellosis compared with normal sera and sera from patients with other helminthiases.

In this study, we identified candidate antigens for early immunodiagnosis and vaccine development against trichinellosis using an immunoproteomics approach. The proteins identified in this study, specifically $T s 14-3-3$ protein, cysteine protease and HSP70, may play critical roles in the maintenance of the host-parasite relationship during the early stage of Trichinella infection, therefore are good targets for vaccine and early immunodiagnosis as well. Except for Ts14-3-3 that has been successfully expressed in E. coli as soluble recombinant protein that can be recognized by Trichinella-infected swine and mouse sera, other identified antigens are also being evaluated for their potential as immunodiagnostic or vaccine reagents using in vitro expression of the recombinant proteins, immunological test for defined infection sera and challenge study with $T$. spiralis infection animal model.

\section{Conclusions}

In this study, 2-DE and Western blot were used to characterize the diagnostic antigens or vaccine candidates from T. spiralis adult worm. A total of 64 proteins from the adult worm were recognized by early infection sera from pigs and mice infected with T. spiralis for 7 days. The proteins identified in this study, especially 14-3-3 protein, possess significant potential as early diagnostic reagents or vaccine candidates.

\section{Competing interests}

The authors declare that they have no competing interests.

\section{Authors' contributions}

JY performed the experiments and drafted the manuscript. WP, XMS, XZ, YG, QS and JJH performed several experiments. XPZ designed the study and revised the manuscript. All authors read and approved the final manuscript.

\section{Acknowledgements \\ This study was supported by grants from the National Natural Science Foundation of China $(81201313,81171598)$, the Natural Science Fundation of Beijing (5122007), and the National Science and Technology Major Project (2012ZX10004220-012). We thank Yuwan Hao, Yaping Yang, Fengyun Wang and Jin Pan for their technical assistance.}

Received: 17 October 2014 Accepted: 4 January 2015

Published online: 13 January 2015

\section{References}

1. Dupouy-Camet J. Presidential address of ICT12 Conference: "Trichinella and trichinellosis-a never ending story". Vet Parasitol. 2009;159(3-4):194-6.

2. Chen MX, Ai L, Xu MJ, Chen SH, Zhang YN, Guo J, et al. Identification and characterization of microRNAs in Trichinella spiralis by comparison with Brugia malayi and Caenorhabditis elegans. Parasitol Res. 2011;109(3):553-8.

3. Pozio E. World distribution of Trichinella spp. infections in animals and humans. Vet Parasitol. 2007;149(1-2):3-21.

4. Wang ZQ, Cui J, Xu BL. The epidemiology of human trichinellosis in China during 2000-2003. Acta Trop. 2006;97(3):247-51.

5. Cui J, Wang ZQ, Xu BL. The epidemiology of human trichinellosis in China during 2004-2009. Acta Trop. 2011;118(1):1-5.

6. Kang SA, Cho MK, Park MK, Kim DH, Hong YC, Lee YS, et al. Alteration of helper T-cell related cytokine production in splenocytes during Trichinella spiralis infection. Vet Parasitol. 2012;186(3-4):319-27.

7. Zocevic A, Mace P, Vallee I, Blaga R, Liu M, Lacour SA, et al. Identification of Trichinella spiralis early antigens at the pre-adult and adult stages. Parasitology. 2011;138(4):463-71.

8. Yepez-Mulia L, Hernandez-Bello R, Arizmendi-Puga N, Fonseca-Linan R, Ortega-Pierres G. Contributions to the study of Trichinella spiralis TSL-1 antigens in host immunity. Parasite Immunol. 2007:29(12):661-70.

9. Dupouy-Camet J, Kociecka W, Bruschi F, Bolas-Fernandez F, Pozio E. Opinion on the diagnosis and treatment of human trichinellosis. Expert Opin Pharmacother. 2002;3(8):1117-30.

10. Gomez-Morales MA, Ludovisi A, Amati M, Cherchi S, Pezzotti P, Pozio E. Validation of an enzyme-linked immunosorbent assay for diagnosis of human trichinellosis. Clin Vaccine Immunol. 2008;15(11):1723-9.

11. Cuttell L, Gomez-Morales MA, Cookson B, Adams PJ, Reid SA, Vanderlinde $P B$, et al. Evaluation of ELISA coupled with western blot as a surveillance tool for Trichinella infection in wild boar (Sus scrofa). Vet Parasitol. 2014;199 (3-4):179-90.

12. Nunez GG, Costantino SN, Venturiello SM. Detection of coproantibodies and faecal immune complexes in human trichinellosis. Parasitology. 2007:134(Pt 5):723-7

13. Zarlenga DS, Boyd P, Lichtenfels JR, Hill D, Ray GH. Identification and characterisation of a cDNA sequence encoding a glutamic acid-rich protein specifically transcribed in Trichinella spiralis newborn larvae and recognised by infected swine serum. Int J Parasitol. 2002:32(11):1361-70.

14. Zhang Y, Wang Z, Li L, Cui J. Molecular characterization of Trichinella spiralis aminopeptidase and its potential as a novel vaccine candidate antigen against trichinellosis in BALB/c mice. Parasit Vectors. 2013;6:246.

15. Krah A, Jungblut PR. Immunoproteomics. Methods Mol Med. 2004;94:19-32.

16. Wang J, Zhao F, Yu CX, Xiao D, Song LJ, Yin XR, et al. Identification of proteins inducing short-lived antibody responses from excreted/secretory products of Schistosoma japonicum adult worms by immunoproteomic analysis. J Proteomics. 2013;87:53-67.

17. Sun XM, Ji YS, Elashram SA, Lu ZM, Liu XY, Suo $X$, et al. Identification of antigenic proteins of Toxoplasma gondii $\mathrm{RH}$ strain recognized by human immunoglobulin G using immunoproteomics. J Proteomics. 2012;77:423-32.

18. Acevedo N, Mohr J, Zakzuk J, Samonig M, Briza P, Erler A, et al. Proteomic and immunochemical characterization of glutathione transferase as a new allergen of the nematode Ascaris lumbricoides. PLoS One. 2013:8(11):e78353.

19. Santivanez SJ, Hernandez-Gonzalez A, Chile N, Oleaga A, Arana Y, Palma S, et al. Proteomic study of activated Taenia solium oncospheres. Mol Biochem Parasitol. 2010;171(1):32-9.

20. Bien J, Nareaho A, Varmanen P, Gozdzik K, Moskwa B, Cabaj W, et al. Comparative analysis of excretory-secretory antigens of Trichinella spiralis and Trichinella britovi muscle larvae by two-dimensional difference gel electrophoresis and immunoblotting. Proteome Sci. 2012;10(1):10.

21. Cui J, Liu RD, Wang L, Zhang X, Jiang P, Liu MY, et al. Proteomic analysis of surface proteins of Trichinella spiralis muscle larvae by twodimensional gel electrophoresis and mass spectrometry. Parasit Vectors. 2013;6:355.

22. Wang L, Cui J, Hu DD, Liu RD, Wang ZQ. Identification of early diagnostic antigens from major excretory-secretory proteins of Trichinella spiralis muscle larvae using immunoproteomics. Parasit Vectors. 2014;7:40.

23. Gamble HR, Bessonov AS, Cuperlovic K, Gajadhar AA, van Knapen F, Noeckler K et al. International Commission on Trichinellosis: recommendations on methods for the control of Trichinella in domestic and wild animals intended for human consumption. Vet Parasitol. 2000;93(3-4):393-408. 
24. Frey CF, Schuppers ME, Nockler K, Marinculic A, Pozio E, Kihm U, et al. Validation of a western blot for the detection of anti-trichinella spp. Antibodies in domestic pigs. Parasitol Res. 2009;104(6):1269-77.

25. Wang B, Wang ZQ, Jin J, Ren HJ, Liu LN, Cui J. Cloning, expression and characterization of a Trichinella spiralis serine protease gene encoding a 35.5 kDa protein. Exp Parasitol. 2013;134(2):148-54.

26. Radoslavov G, Jordanova R, Teofanova D, Georgieva K, Hristov P, SalomoneStagni $M$, et al. A novel secretory poly-cysteine and histidine-tailed metalloprotein (Ts-PCHTP) from Trichinella spiralis (Nematoda). PLoS One. 2010;5(10):e13343.

27. Liu $P$, Wu XP, Bai $X$, Wang $X L, Y u$, Rosenthal $B$, et al. Screening of early antigen genes of adult-stage Trichinella spiralis using pig serum from different stages of early infection. Vet Parasitol. 2013;194(2-4):222-5.

28. Wang ZQ, Wang L, Cui J. Proteomic analysis of Trichinella spiralis proteins in intestinal epithelial cells after culture with their larvae by shotgun LC-MS/ MS approach. J Proteomics. 2012;75(8):2375-83.

29. Sotillo J, Valero L, Sanchez DPM, Fried B, Esteban JG, Marcilla A, et al. Identification of antigenic proteins from Echinostoma caproni (Trematoda) recognized by mouse immunoglobulins $M, A$ and $G$ using an immunoproteomic approach. Parasite Immunol. 2008;30(5):271-9.

30. Colaco CA, Bailey CR, Walker KB, Keeble J. Heat shock proteins: stimulators of innate and acquired immunity. Biomed Res Int. 2013;2013:461230.

31. Kaur J, Kaur S. ELISA and western blotting for the detection of Hsp70 and Hsp83 antigens of Leishmania donovani. J Parasit Dis. 2013;37(1):68-73.

32. Liu F, Cui SJ, Hu W, Feng Z, Wang ZQ, Han ZG. Excretory/secretory proteome of the adult developmental stage of human blood fluke, Schistosoma japonicum. Mol Cell Proteomics. 2009;8(6):1236-51.

33. Kanamura HY, Hancock K, Rodrigues V, Damian RT. Schistosoma mansoni heat shock protein 70 elicits an early humoral immune response in $S$. mansoni infected baboons. Mem Inst Oswaldo Cruz. 2002;97(5):711-6.

34. Wang S, Zhu X, Yang Y, Yang J, Gu Y, Wei J, et al. Molecular cloning and characterization of heat shock protein 70 from Trichinella spiralis. Acta Trop. 2009;110(1):46-51.

35. Fang L, Sun L, Yang J, Gu Y, Zhan B, Huang J, et al. Heat shock protein 70 from Trichinella spiralis induces protective immunity in BALB/C mice by activating dendritic cells. Vaccine. 2014;32(35):4412-9.

36. Sajid M, McKerrow JH. Cysteine proteases of parasitic organisms. Mol Biochem Parasitol. 2002;120(1):1-21.

37. Jorgensen L, Buchmann K. Cysteine proteases as potential antigens in antiparasitic DNA vaccines. Vaccine. 2011:29(34):5575-83.

38. Pina R, Gutierrez AH, Gilman RH, Rueda D, Sifuentes C, Flores M, et al. A dotELISA using a partially purified cathepsin-L-like protein fraction from Taenia solium cysticerci, for the diagnosis of human neurocysticercosis. Ann Trop Med Parasitol. 2011;105(4):311-8.

39. Rabee I, Mahana NA, Badr AM. Immunodiagnosis of Egyptian human fasciolosis gigantica using Fas1 and Fas2 cysteine proteinase antigens. J Egypt Soc Parasitol. 2013;43(3):787-96.

40. Mrowiec T, Schwappach B. 14-3-3 proteins in membrane protein transport. Biol Chem. 2006:387(9):1227-36.

41. Obsil T, Obsilova V. Structural basis of 14-3-3 protein functions. Semin Cell Dev Biol. 2011;22(7):663-72.

42. Lee MR, Kim YJ, Kim DW, Yoo WG, Cho SH, Hwang KY, et al. The identification of antigenic proteins: 14-3-3 protein and propionyl-CoA carboxylase in Clonorchis sinensis. Mol Biochem Parasitol. 2012;182(1-2):1-6.

43. Luo QL, Qiao ZP, Zhou YD, Li XY, Zhong ZR, Yu YJ, et al. Application of signaling protein 14-3-3 and $26 \mathrm{kDa}$ glutathione-S-transferase to serological diagnosis of Schistosomiasis japonica. Acta Trop. 2009;112(2):91-6.

44. Li ZJ, Wang YN, Wang Q, Zhao W. Echinococcus granulosus 14-3-3 protein: a potential vaccine candidate against challenge with Echinococcus granulosus in mice. Biomed Environ Sci. 2012;25(3):352-8.

45. Schechtman D, Tarrab-Hazdai R, Arnon R. The 14-3-3 protein as a vaccine candidate against schistosomiasis. Parasite Immunol. 2001;23(4):213-7.

\section{Submit your next manuscript to BioMed Central and take full advantage of:}

- Convenient online submission

- Thorough peer review

- No space constraints or color figure charges

- Immediate publication on acceptance

- Inclusion in PubMed, CAS, Scopus and Google Scholar

- Research which is freely available for redistribution

Submit your manuscript at www.biomedcentral.com/submit 